\title{
NOVA MUTAÇÃO NO GENE CD4OLG EM PACIENTE COM FENÓTIPO BRANDO DE SÍNDROME DE HIPER- IGM LIGADA AOX
}

Pôster

Autores deste trabalho:

Tábata Takahashi França: MSc, Instituto de Ciências Biomédicas, Departamento de Imunologia, Universidade de São Paulo, SP, Brasil

Luiz Fernando Bacarini Leite: MD, Setor de Imunodeficiências, Departamento de Pediatria, Irmandade da Santa Casa de Misericórdia de São Paulo, SP, Brasil.

Tiago Arruda Maximo: MD, Setor de Imunodeficiências, Departamento de Pediatria, Irmandade da Santa Casa de Misericórdia de São Paulo, SP, Brasil.

Christiane Guedes Lambert: MCs, Instituto de Ciências Biomédicas, Departamento de Imunologia, Universidade de São Paulo, SP, Brasil.

Nuria Bengala Zurro: MSc, Instituto de Ciências Biomédicas, Departamento de Imunologia, Universidade de São Paulo, SP, Brasil.

Wilma Carvalho Neves Forte: MD, Disciplina de Imunologia, Escola de Ciências Médicas da Santa Casa de São Paulo, SP, Brasil.

Antonio Condino Neto: Instituto de Ciências Biomédicas, Departamento de Imunologia, Universidade de São Paulo, SP, Brasil.

Área do Trabalho: Pediatria

Data da submissão: 14/08/2018 às 18:17

\section{Justificativa}

Mutações no gene do CD40 ligante (CD40L) levam à Síndrome de Hiper-IgM ligada ao $X(X-H I G M)$, imunodeficiência primária caracterizada por níveis séricos normais ou elevados de IgM associados a níveis reduzidos de IgG e IgA. Embora a maioria dos pacientes com X-HIGM se tornem sintomáticos no primeiro ou segundo ano de vida, alguns pacientes exibem fenótipos brandos normalmente associados a mutações hipomórficas que prejudicam a função ou expressão do CD40L, embora mantenham a atividade residual da molécula.

\section{Objetivo(s)}

Diagnóstico de imunodeficiência primária.

\section{Método(s)}

Amostra de sangue periférico do paciente e de um indivíduo sadio foram coletadas em tubo de heparina para o isolamento de linfócitos. A expressão do CD40L foi avaliada por citometria de fluxo em células $C D 3+C D 4+$ não ativadas ou ativadas. $A$ análise genética do paciente foi realizada pelo sequenciamento do gene CD4OLG pelo método de Sanger.

\section{Resultado(s)}

Este trabalho foi realizado de acordo com a resolução 466/12 e aprovado em Comitê de Ética em Pesquisa (02877912.2.3001.5567). Neste trabalho descrevemos o caso 


\section{$4^{\circ}$ Congresso Internaciona! Sabaró \\ 13 a 15 de \\ 13 a 15 de 2018}

Hotel Maksoud Plaza
Alameda Campinas, 150
Säo Pavio-Brosil

de um paciente de 28 anos de idade, sexo masculino, que apresentou histórico clínico de infecções de repetição desde os 7 anos. Baseado no histórico clínico e laboratorial o paciente foi inicialmente diagnosticado com Imunodeficiência Comum Variável. A avaliação da expressão do CD40L na superfície de células T CD3+CD4+ ativadas mostrou uma redução na expressão da molécula. A análise genética do gene CD40LG do paciente revelou uma nova mutação de novo caracterizada pela inserção de seis nucleotídeos no exon 1 do gene, confirmando o diagnóstico de X-HIGM do paciente.

\section{Conclusão (ões)}

Os resultados descrevem uma nova mutação no gene CD4OLG e destacam a complexidade no diagnóstico das imunodeficiências primárias em face da apresentação de fenótipos atípicos e de mutações hipomórficas. 